\title{
Serbest Stil Güreşçilerde 8 Haftalık Core Egzersizlerinin Maksimal Kuvvet, Dikey Siçrama Ve Esneklik Üzerine Olan Etkisinin İncelenmesi
}

\begin{abstract}
DOI: $10.26466 /$ opus. 856167
Ercan Tural $^{*}$ - Sedat Kahya ${ }^{* *}$ - Abdullah Tiryaki ${ }^{* * *}$ Mehmet Çebi ${ }^{* \star * *}$ - Levent Ceylan ${ }^{* \star * *}$

***** Dr.Öğr. Üyesi, Sivas Cumhuriyet Üniversitesi, Spor Bilimleri Fakültesi

E-Posta: ercant@omu.edu.tr

ORCID: $\underline{0000-0003-3894-7761}$

* Dr.Öğr.Üyesi, Ondokuz Mayis Üniversitesi/Sağlik Bilimleri Fakültesi/Fizyoterapi ve Rehabilitasyon Bölümü/Fizyoterapi ve Rehabilitasyon Anabilim Dalı, Samsun/Türkiye

E-Posta: sedatkayha58@gmail.com

ORCID: $\quad$ 0000-0002-1169-2642

**Öğretmen, Sivas Ahmet Ayık Spor Lisesi, Sivas/Türkiye

E-Posta: atiryaki380@gmail.com

ORCID: 0000-0002-2294-5131

***Öğretmen, Sivas Ahmet Ayık Spor Lisesi, Sivas/Türkiye

E-Posta mehmet.cebi@omu.edu.tr

ORCID: 0000-0002-4055-728X

**** Doç., Ondokuz Mayis Üniversitesi/Yaşar Doğu Spor Bilimleri Fakültesi/Rekreasyon Bö-

lümü/Rekreasyon Anabilim Dali, Samsun/Türkiye

E-Posta leventceylan@cumhuriyet.edu.tr ORCID: $\quad$ 0000-0002-3045-1211

Öz

Bu çalışmada amaç; Sivas merkez Ahmet Ayık Tematik Spor Lisesinde öğrenim gören 15-17 yaş arası serbest stil müsabık sporculara uygulanan 8 haftalk kor egzersizlerinin maksimal kuvvet, (bacak, strt ve kavrama

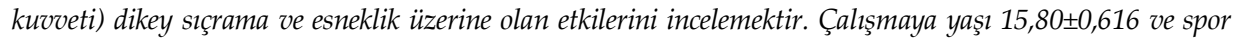

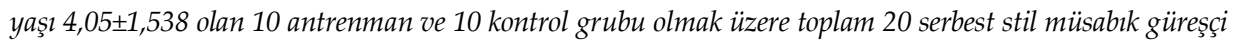
katılmıştır. Çalışmaya katılanlardan sporcuların boy uzunluğu, vücut ağırllğı, kor gücü ve stabilitesi, dikey sıçrama, uzan eriş ve sırt, bacak ve kavrama kuvveti ön test ve son test olmak üzere ölçümleri alınmıştır. Antrenman ve kontrol gruplarmın egzersiz öncesi ve sonrası değişimin belirlenmesinde Wilcoxon testi ve betimsel analiz testi uygulanmıştır. Antrenman grubunun antrenman öncesi ve sonrası sırt kuvveti, boy ve VKİ değişkeninde anlaml farklllk bulunmuştur $(p<0,05)$. Kor kuvvet antrenman öncesi ve antrenman sonrası kilo, uzan eriş, bacak, sağ ve sol kavrama ve kor kuvveti anlamlı farklılık bulunmamıştır ( $p>0,05)$. Sonuç olarak 8 haftalık kor kuvvet antrenmanlarmmn serbest stil erkek güreşçilerin sırt kuvveti üzerine olumlu etkileri olduğu söylenebilir.
\end{abstract}

Anahtar Kelimeler: Kor antrenman, Serbest stil güreş, Kuvvet, Sıçrama, Esneklik. 
ISSN: 2528-9527

E-ISSN : 2528-9535

Yıl Year: 11

Cilt Volume: 17

Sayı Issue:37

\title{
Investigation of The Effects of 8 Weeks of Core Exercises on Maximal Strength, Vertical Jump and Flexibility in Free Style Wrestlers
}

\begin{abstract}
The purpose of this study; To examine the effects of 8-week core exercises on maximal strength (leg, back and paw strength), vertical jump and flexibility, applied to freestyle contestant athletes between 15-17 years of age at Sivas Ahmet Ayık Thematic Sports High School. A total of 20 freestyle wrestlers, 10 training and 10 control groups, with an age of $15.80 \pm 0.616$ and sports age of $4.05 \pm 1.538$, participated in the study. The measurements of the athletes' height, body weight, core strength and stability, vertical jump, reach and back, leg and claw strength as pre-test and post-test were taken. Wilcoxon test and descriptive analysis test were used to determine the change in training and control groups before and after exercise. A significant difference was found in the variables of back strength, height and BMI of the training group before and after training. There was no significant difference in weight, reach, leg, right and left hand claw and core strength before and after the core strength training. As a result, it can be said that 8-week core strength training has positive effects on back strength of freestyle male wrestlers.
\end{abstract}

Keywords: Core training, Freestyle wrestling, Strength, Bounce, Flexibility 


\section{Giriş}

Sportif performansın geliştirilmesinde kor kuvvetinin iyileştirilmesi antrenman biliminde üzerinde sıklıkla tartışılan bir konudur. Güçlü kor kasları, günlük rutin faaliyetlerimizi sürdürebilmemizin yanı sıra başarılı bir sportif performans için de gereklidir (Becer ve Eliöz, 2020, s.891). Kor, güçlü alan olarak bütün hareketleri başlatan vücudun ana merkezi olarak tanımlanır. Kor kuvveti, omurganın fonksiyonunu sürdürebilmesinde önemli kassal bir yapıdır (Karacabey, Tetik, Kartal, Çağlayan, ve Kaya, 2016, s.63). Kor, vücudun lumbopelvik bölgesi veya gövde kısmı için kullanılan (Sever, Kır ve Yaman, 2017, s. 3023) ön tarafta karın kasları, arkada sırt kasları, ön üstte diyafram ile altta pelvik taban kaslarını içeren geniş bir kastır (Gür ve Ersöz, 2017, s. 130). Bu kassal yapının özellikle egzersizler yardımıyla kuvvetlendirilmesi sportif performans için oldukça önemlidir. Kor kuvveti egzersizleri, kalça ve omugayı dengeleyen ve çoğu kuvvet çalışmalarında sıklıkla kullanılan bir metottur. Diğer taraftan kor egzersizleri, sporcunun bir direnç karşısında ki kuvvetini de geliştiren bir uygulamadır (Atan, Kabadayı, Eliöz, Çilhoroz, ve Akyol, 2013, s. 74). Günümüzde kor, atletik performans geliştirmek için popüler bir hedef olmasının yanı sira (Reed, Ford, Myer ve Hewett, 2014, s. 697) proksimal sabitlik için distal hareketliliğe de yardımcı olan bir yapıdır (Kibler, Press ve Aaron, 2006, s. 189). Kor egzersizleri, sakatlikları önlemek ve uygun bir performans için yapılması zorunlu bir uygulamadır (McGill, 2020, s. 34). Bir çok spor branşında büyük bir öneme sahip olan kor, özellikle dünyanın en popüler spor branşlarından biri olan güreşte (Bayati, Majelan, Mirzeali ve Barbas, 2019, s. 40) sporcunun hem alt hem de üst vücut için büyük bir kuvvet ve kas gücü üretmesi (Bal, Singh, Singh ve Singh, 2018, s. 100) sportif performans, motor kapasite, denge gelişimi, rehabilitasyon ve sakatlıkların önlenmesi bakımından büyük bir öneme sahiptir (Afyon, 2014, s. 1275; Küçük, 2020, s. 54; Küçük ve Erim, 2021, s. 2).

Ayrıca kor egzersizleri, dinamik denge ile fonksiyonel kuvvetin artırılmasına da destek sağlamaktadır (Samson ve Sandery, 2007, s. 41). İnsanlık tarihinin büyük fiziksel aktivitelerinden olan güreş (Mırzaelı, Curby, RahmanıNia ve Moghadasi, 2009, s. 2339) ani şekilde itme, çekme ve yere düşme gibi hareketlerin sıklıkla uygulanmasının yanı sıra müsabakaların ve antrenmanların yapıldığı zeminin de yumuşak yapıda olması sebebiyle iyi bir denge performansı için güçlü bir kor kuvveti geliştirmede önemli bir faktördür (İri 
ve Aktuğ, 2018, s. 81). Özellikle serbest stil güreş, vücudun üst ve alt bölümlerini içeren kısa süreli, aralıklı ve yüksek yoğunluklu bir faaliyet olması bakımdan (Demirkan, Kutlu, Koz, Özal, ve Favre, 2014, s.246) kor kuvveti için büyük önem arz etmektedir.

Kor antrenmanın birçok branşta olduğu gibi Güreş branşında da önemli etkileri olduğunu söyleyebiliriz. Çalışmamızın amacını, özellikle 15-17 yaş arası serbest stil müsabık güreşçilerin 8 haftalık kor egzersizleri sonrası maksimal kuvvet, dikey sıçrama ve esneklik seviyelerinin incelenmesi oluşturmaktadır. Düzenli kor egzersizlerinin serbest stil güreşçilerde maksimal kuvvet, esneklik, dikey sıçrama becerileri ile ilişkisinin tespit edilmesi genç sporculara uygulanacak antrenman programlarının tespit edilmesi açısından önemlidir. Bu sebeple yapılan çalışmada amaç serbest stil güreş antrenmanlardan sonra yapılan düzenli kor egzersizlerinin maksimal kuvvet, esneklik ve dikey sıçrama becerilerin üzerine etkisini tespit etmektir.

\section{Yöntem}

\section{Araştırma Grubu}

Araştırmaya, 2019-2020 eğitim öğretim yılında aralık ayı itibariyle Ahmet

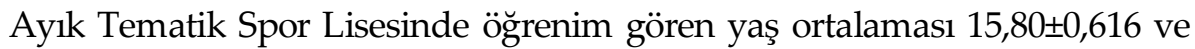

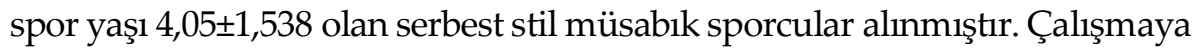
okulun güreş salonunda düzenli güreş antrenmanı yapan müsabık sporcular, tesadüfi örnekleme yöntemi kullanılarak 20 serbest stil güreşçi, 10 antrenman ve 10 kontrol grubu olmak üzere çalışmaya dahil edilmiştir.

\section{Boy Uzunluğu ve Vücut Ă̆grlığı Ölçümü}

Çalışmaya katılan sporcuların, boy uzunlukları ve vücut ağırlıkları çalışma öncesi ve sonrası olmak üzere 2 kez ölçülmüsstür. Ağırlık ölçümünde Bluelight marka BYF10 model \pm 100 gr hassasiyetli dijital baskül ve boy ölçümünde ise holtain marka, hassasiyeti $\pm 1 \mathrm{~mm}$ boy ölçer kullanıldı. Ölçümler sonucunda elde edilen değer $\mathrm{cm}$ (boy) ve $\mathrm{kg}$ (kilo) cinsinden kayıt altına alınmıştır. Vücut kitle indeksi (VKİ) ise vücut ağırlı̆̆ının kilogram (kg) değerinin, boy uzunluğu metre (m) ölçümünün karesine bölünmesi ile (kg/m2 ) hesaplanmıştır. 


\section{Strt Kuvveti ve Bacak Kuvveti}

1-RM kuvvet testi protokollerine uygun olarak sırt ve bacak kuvveti ölçümü için Takei marka ölçüm cihazı kullanılmıştır. (ölçüm aralığı 20 ile 300 kg) Sırt kuvveti için sporculardan ayaklarını dinamometrenin üzerine yerleştirerek sırt düz öne hafif eğilerek dizler maksimum şekilde sirt ekstansiyon yapana kadar dinamometreyi çekmeleri istenmiştir. Bacak kuvveti ise aynı şekilde sporcuların ayaklarını dinamometrenin üzerine yerleştirmeleri suretiyle bacaklarını maksimum şekilde ekstansiyon yapana kadar (sırt kuvvetini kullanmadan) çekmeleri istenmiştir. Uygulama dinlenme aralıkları verilerek en az 2 deneme şeklinde gerçekleştirilmiştir. En iyi dereceleri kg olarak kaydedilmiştir. Hareketin uygulanmasında hatalar görüldüğü an çalışma durdurulmuştur.

\section{Kavrama Kuvveti}

2-0286 Basline marka el dinamometresi yardımıyla sporcuların sağ ve sol elleri olmak üzere kavrama kuvvetleri ölçülmüştür. Sporculardan kavrama aletini, tam kavrayacakları şekilde ayarlamaları istenerek maksimum şekilde aleti sıkmaları istenmiştir. Dinlenmek suretiyle en az 2 deneme hakkı verilerek en iyi dereceleri kg olarak kaydedilmiştir. Hareketin uygulanmasında hatalar görüldüğü an çalışma durdurulmuş̧tur.

\section{Uzan Eriş Testi}

Uzan-eriş sehpası, ayakların yerleştirildiği yerden başlayarak 0 noktasından $15 \mathrm{~cm}$ 'lik bir çıkıntıya sahip bir araçtır. Uzan-eriş sehpası kullanılarak sporculardan ayak tabanlarını uzan-eriş sehpasının duvar kısmına yerleştirerek dizlerini sıkı bir şekilde bükmeden sehpaya dayayarak iki eli ile ileriye doğru uzanabildiği kadar uzanmaları istenmiştir. Ardından orta parmağın ulaştığı en uzun nokta cm olarak kaydedilmiştir. Dinlenme aralıkları verilerek sporculara en az 2 deneme hakkı verilmiştir. Hareketin uygulanmasında hatalar görüldüğü an çalışma durdurulmuştur.

\section{Dikey sıçrama}

Sporcuların dikey sıçramaları, Takei Jump Meter marka cihaz ile ölçülmüştür. Sporcunun alet üzerinde sabit kalması suretiyle bedenini maksimal şekilde yukarıya doğru fırlatmasıyla hareket gerçekleştirilmiştir. Uygulama iki 
kez yapılarak ve en iyi sonuç cm cinsinden kaydedilmiştir. Hareketin uygulanmasında hatalar görüldüğü an çalışma durdurulmuştur.

\section{Sporcularnn Kor Gücü ve Stabilitesi Ölçümü}

Mackenzie, (2005) tarafından geliştirilen Core Muscle Strenght and Stability testi ile ölçüm gerçekleştirilmiştir. Testin uygulanması düz bir zeminde, mat, kronometre ve bir yardımc ile yapıldı. Kor stabilizasyon testinin uygulanması süresince hareketler plank pozisyonunda yapılmıştır. Plank pozisyonu bozulduğu anda test sona erdirilmiştir. Testin uygulanması toplam 8 aşamadan oluşmuştur. 180 saniyelik süre içerisinde test gerçekleştirilmiştir. Sporcular, testin bütün aşamalarını tamamladığı zaman başarılı sayılmışlardır.

\section{Verilerin Toplanmast}

Test uygulanmadan önce kurumla görüşülerek ve gerekli izinler alınmıştır. Ardından çalışmaya katılacak olan öğrencilere yapılacak testlerin amacı ayrıntıları ile anlatışmış gerekli bilgiler verilmiştir. Çalışmaya alınan denek grubu, güreş antrenörü ve çalışma sorumlusu personel eşliğinde 8 hafta boyunca rutin güreş antrenmanları sonrası önceden belirlenen Kor egzersiz programına alınmıştır. Kontrol grubu ise 8 hafta boyunca rutin güreş antrenman programlarını uygulamışlardır. Denek grubuna ilk antrenmandan 1 hafta önce çalışmadan tam verim alabilmek için antrenman programındaki kor egzersizleri deneme amaçlı sırası ile uygulatılmıştır. Hatalar düzeltilmiş ve hareketlerin istenilen şekilde yapılması sağlanmıştır. Bu şekilde sporcular, ortak egzersiz hareket kabiliyeti kazanma yönünde senkronize edilmişlerdir. Ayrıca çalışma ve kontrol gruplarının 8 haftalık egzersiz programının başında ve sonunda olmak üzere iki kez antropometrik ölçümleri (vücut ağırlığı ve boy uzunluğu), maksimal kuvvet ölçümleri (bacak kuvveti, sırt kuvveti ve kavrama kuvveti), esneklik (uzan eriş), dikey sıçrama ve kor stabilizasyon kuvvet ölçüm skorları alınmıştır.

\section{Çalışmada Uygulanan 8 Haftalık Kor Egzersiz Programı}

$\mathrm{Bu}$ araştırmada kullanılan kor antrenman programı Willardson'ın (2014), "Developing the Core" isimli kitabı temel alınarak oluşturulmuştur. Antrenman programı 8 hafta boyunca haftada 3 gün (pazartesi, çarşamba ve cuma) gerçekleştirilmiştir. Kor antrenmanın esas hareketi olan Plank pozisyonunun 
gövde bölgesinin ön, yan ve sırt adalelerini çalıştıran değişik seçenekleri sabit stilde uygulanmıştır.

Tablo 1. Haftalik kor antrenman programı

\begin{tabular}{lllllll}
\hline $\begin{array}{l}\text { Kor Egzersiz } \\
\text { Sayıs1 }\end{array}$ & Hafta & Gün & Set & Tekrar & Süre/Sn & Dinlenme/Sn \\
\hline 12 & 1 & 3 gün & $1 \times$ & 2 & $2 \times 30^{\prime \prime}$ & $2 \times 45^{\text {ce }}$ \\
\hline 12 & 2 & 3 gün & $1 \mathrm{x}$ & 2 & $2 \times 30^{\prime \prime}$ & $2 \times 45^{\text {ee }}$ \\
\hline 12 & 3 & 3 gün & $1 \mathrm{x}$ & 2 & $2 \times 30^{\prime \prime}$ & $2 \times 45^{\text {ee }}$ \\
\hline 12 & 4 & 3 gün & $1 \mathrm{x}$ & 2 & $2 \times 30^{\prime \prime}$ & $2 \times 45^{\text {ce }}$ \\
\hline 12 & 5 & 3 gün & $1 \mathrm{x}$ & 2 & $2 \times 45^{\prime \prime}$ & $2 \times 60^{\text {ce }}$ \\
\hline 12 & 6 & 3 gün & $1 \mathrm{x}$ & 2 & $2 \times 45^{\prime \prime}$ & $2 \times 60^{\text {ce }}$ \\
\hline 12 & 7 & 3 gün & $2 \mathrm{x}$ & 2 & $2 \times 45^{\prime \prime}$ & $2 \times 60^{\text {ee }}$ \\
\hline 12 & 8 & 3 gün & $2 \times$ & 2 & $2 \times 45^{\prime \prime}$ & $2 \times 60^{\text {ee }}$ \\
\hline
\end{tabular}

\section{İstatistiksel Analiz}

Araştırmada Shapiro-Wilk testi neticesinde verilerin normal dağılım göstermediği tespi edilmiştir $(p<0,05)$. istatistiksel yöntem olarak verilerin normal dağılmadığı bulunmuştur. Antrenman ve kontrol gruplarının Egzersiz öncesi ve sonrası değişimin belirlenmesinde non parametrik testlerden Wilcoxon testi ve ortalamaların alınması için de betimsel test uygulanmıştır. İstatistiksel önem düzeyi $\mathrm{p}<0.05$ olarak kabul edilmiştir.

Bu çalışma, B.30.2.ODM.0.20.08/870 sayılı OMÜ KAEK 2020/739 karar nolu Ondokuz Mayıs Üniversitesi Klinik Araştırmalar Etik Kurulu tarafından etik açıdan onaylanmıştır.

\section{Bulgular}

Tablo 2. Antrenman grubunun ölçüm öncesi ve sonrası fiziksel parametrelerinin ortalamalar

\begin{tabular}{|c|c|c|c|c|}
\hline Değişkenler & $\mathbf{n}$ & $\begin{array}{l}\text { Antrenman } \\
\text { Ortalama } \pm S S\end{array}$ & $\begin{array}{r}\text { ÖncesiAntrenman } \\
\text { Ortalama } \pm S S\end{array}$ & Sonras1 \\
\hline Boy & 10 & $170,60 \pm 6,61$ & $171,70 \pm, 6,701$ & \\
\hline Kilo & 10 & $64,40 \pm 6,80$ & $64,10 \pm 6,20$ & \\
\hline VKİ & 10 & $22,12 \pm 1,46$ & $21,73 \pm 1,34$ & \\
\hline Bacak Kuvveti (kg) & 10 & $117,80 \pm 32,17$ & $120,55 \pm 23,19$ & \\
\hline Sirt Kuvveti (kg) & 10 & $105,80 \pm 25,41$ & $124,55 \pm 24,38$ & \\
\hline Sağ El Kavrama Kuvveti (kg) & 10 & $37,35 \pm 6,23$ & $38,96 \pm 4,66$ & \\
\hline Sol El Kavrama Kuvveti (kg) & 10 & $38,58 \pm 5,32$ & $38,38 \pm 4,95$ & \\
\hline Uzan Eriş $(\mathrm{cm})$ & 10 & $43,75 \pm 7,83$ & $46,45 \pm 5,98$ & \\
\hline Dikey Siçrama (cm) & 10 & $60,90 \pm 11,47$ & $55,30 \pm 7,18$ & \\
\hline Kor Kuvveti (sn) & 10 & $158,20 \pm 24,48$ & $168,10 \pm 12,62$ & \\
\hline
\end{tabular}


Tablo 2' de katılımcların kor kuvvet antrenmanından önce ve sonrası yapılan fiziksel ölçümlerin ortalamaları verilmiştir. Antrenman sonunda bu parametrelerden kilo, VKİ ve sol el kavrama kuvveti ortalamalarının düştüğü, diğer parametrelerin artı̆̆ görülmüş̧tür.

Tablo 3. Antrenman grubunun ölçüm öncesi ve sonrası fiziksel parametrelerinin

\section{karşılaştırılması}

\begin{tabular}{|c|c|c|c|c|c|c|}
\hline \multicolumn{2}{|c|}{$\begin{array}{l}\text { Antrenman Öncesi ve } \\
\text { Sonrası Parametreler }\end{array}$} & \multirow{2}{*}{$\begin{array}{l}\mathbf{n} \\
0^{\mathrm{a}}\end{array}$} & \multirow{2}{*}{$\begin{array}{l}\text { Ortanca } \\
00 \\
\end{array}$} & \multirow{2}{*}{$\begin{array}{l}\text { Toplamları } \\
, 00 \\
\end{array}$} & \multirow{5}{*}{$\begin{array}{l}\mathbf{Z} \\
-2,232 \\
\end{array}$} & \multirow{5}{*}{$\begin{array}{l}\mathbf{P} \\
, 026\end{array}$} \\
\hline \multirow{4}{*}{ Boy } & Negatif Srralama & & & & & \\
\hline & Pozitif Siralama & $6^{\mathrm{b}}$ & 3,50 & 21,00 & & \\
\hline & Aynı değer & $4^{c}$ & & & & \\
\hline & Toplam & 10 & & & & \\
\hline \multirow{4}{*}{ Kilo } & Negatif Siralama & $4^{\mathrm{a}}$ & 3,38 & 13,50 & \multirow{4}{*}{-647} & \multirow{4}{*}{, 518} \\
\hline & Pozitif Siralama & $2^{b}$ & 3,75 & 7,50 & & \\
\hline & Aynı değer & $44^{c}$ & & & & \\
\hline & Toplam & 10 & & & & \\
\hline \multirow{4}{*}{ VKİ } & Negatif Sıralama & $7^{\mathrm{a}}$ & 4,71 & 33,00 & \multirow{4}{*}{$-2,100$} & \multirow{4}{*}{,036 } \\
\hline & Pozitif Siralama & $1^{\mathrm{b}}$ & 3,00 & 3,00 & & \\
\hline & Aynı değer & $2^{c}$ & & & & \\
\hline & Toplam & 10 & & & & \\
\hline \multirow{4}{*}{ Bacak kuvveti } & Negatif Siralama & $5^{\mathrm{a}}$ & 5,20 & 26,00 & \multirow{4}{*}{-153} & \multirow{4}{*}{,878 } \\
\hline & Pozitif Sıralama & $5^{b}$ & 5,80 & 29,00 & & \\
\hline & Aynı değer & $0 c$ & & & & \\
\hline & Toplam & 10 & & & & \\
\hline \multirow{4}{*}{ Sirt kuvveti } & Negatif Sıralama & $2^{a}$ & 3,50 & 7,00 & \multirow{4}{*}{$-2,091$} & \multirow{4}{*}{,037 } \\
\hline & Pozitif Siralama & $8^{\mathrm{b}}$ & 6,00 & 48,00 & & \\
\hline & Aynı değer & $0^{c}$ & & & & \\
\hline & Toplam & 10 & & & & \\
\hline \multirow{4}{*}{$\begin{array}{l}\text { Sağ El } \\
\text { Kavrama Kuvveti }\end{array}$} & Negatif Sıralama & $5^{\mathrm{a}}$ & 4,80 & 24,00 & \multirow{4}{*}{,- 357} & \multirow{4}{*}{,721 } \\
\hline & Pozitif Suralama & $5^{b}$ & 6,20 & 31,00 & & \\
\hline & Aynı değer & $0^{c}$ & & & & \\
\hline & Toplam & 10 & & & & \\
\hline \multirow{4}{*}{$\begin{array}{l}\text { Sol El } \\
\text { Kavrama Kuvveti }\end{array}$} & Negatif Siralama & $5^{\mathrm{a}}$ & 4,60 & 23,00 & \multirow{4}{*}{,- 059} & \multirow{4}{*}{,953 } \\
\hline & Pozitif Suralama & $4^{\mathrm{b}}$ & 5,50 & 22,00 & & \\
\hline & Aynı değer & $1^{c}$ & & & & \\
\hline & Toplam & 10 & & & & \\
\hline \multirow{4}{*}{ Uzan Eriş } & Negatif Siralama & $2^{a}$ & 2,75 & 5,50 & \multirow{4}{*}{$-1,755$} & \\
\hline & Pozitif Siralama & $6^{\mathrm{b}}$ & 5,08 & 30,50 & & \\
\hline & Aynı değer & $2^{c}$ & & & & ,079 \\
\hline & Toplam & 10 & & & & \\
\hline & Negatif Sıralama & $7 \mathrm{a}$ & 6,00 & 42,00 & & \\
\hline Dikev Syram & Pozitif Siralama & $3^{\mathrm{b}}$ & 4,33 & 13,00 & 1481 & 139 \\
\hline Dikey Siçrama & Aynı değer & $0^{c}$ & & & $-1,481$ & , 139 \\
\hline & Toplam & 10 & & & & \\
\hline Kor Kuvveti & Negatif Sıralama & $3^{a}$ & 4,00 & 12,00 & -840 & 401 \\
\hline
\end{tabular}




\begin{tabular}{lllll}
\hline Pozitif Siralama & $5^{\mathrm{b}}$ & 4,80 & 24,00 \\
\cline { 2 - 4 } & Aynı değer & $2^{\mathrm{c}}$ & & \\
\cline { 2 - 4 } & Toplam & 10 & & \\
\hline
\end{tabular}

a. Antrenman sonrası < antrenman öncesi

b. Antrenman sonras1 > antrenman öncesi

c. Antrenman sonras1 = antrenman öncesi

Tablo 3'de antrenman öncesi ve antrenman sonrası ölçüm değerlerine baktığımızda aynı boyda olan birey sayısı 4, pozitif olan birey sayısı ise 6 olmuştur. Antrenman grubunun aynı kiloda olanlar 4, kilosu negatif yönde azalan 4 ve pozitif yönde artan 2 olmuştur. VKİ değerleri aynı olan 2, negatif yönde azalan 7 ve pozitif yönde artan 1 olmuştur. Bacak kuvveti ve sağ el kavrama kuvveti değerleri negatif yönde azalan 5 ve pozitif yönde artan 5 olmuştur. Sırt kuvveti değerleri negatif yönde azalan 2 ve pozitif yönde artan 8 olmuştur. Sol el kavrama kuvveti değerleri aynı olan 1 , negatif yönde azalan 5 ve pozitif yönde artan 4 olmuştur. Uzan eriş değerleri aynı olan 2, negatif yönde azalan 2 ve pozitif yönde artan 6 olmuştur. Dikey sıçrama verileri negatif yönde azalan 7 ve pozitif yönde artan 3 olmuştur. Kor kuvveti aynı olan 2, negatif yönde azalan 3 ve pozitif yönde artan 5 olmuştur. Sırt kuvveti, boy ve VKİ değerlerinde anlamlı bir farklılık vardır $(p<0,05)$. Bireylerin diğer değişkenleri arasında anlamlı farklılık bulunmamıştır ( $p>0,05)$.

Tablo 4. Kontrol grubunun ölçüm öncesi ve sonrası fiziksel parametrelerinin ortalamalar

\begin{tabular}{llll}
\hline Değişkenler & $\mathbf{n}$ & $\begin{array}{l}\text { Ön Test Ortalama } \\
\text { SS Son Test Ortalama } \pm \text { SS }\end{array}$ \\
\hline Boy & 10 & $178,30 \pm 7,40$ & $179,30 \pm 6,89$ \\
\hline Kilo & 10 & $81,50 \pm 20,30$ & $81,20 \pm 18,68$ \\
\hline VKI & 10 & $25,37 \pm 4,38$ & $25,07 \pm 4,43$ \\
\hline Bacak Kuvveti & 10 & $133,80 \pm 33,59$ & $153,50 \pm 44,02$ \\
\hline Sırt Kuvveti & 10 & $127,85 \pm 35,76$ & $148,85 \pm 30,62$ \\
\hline Să̆ El Kavrama Kuvveti & 10 & $39,39 \pm 13,15$ & $44,85 \pm 9,31$ \\
\hline Sol El Kavrama Kuvveti & 10 & $37,64 \pm 15,31$ & $41,82 \pm 8,86$ \\
\hline Uzan Eriş & 10 & $39,45 \pm 10,19$ & $42,20 \pm 8,20$ \\
\hline Dikey Siçrama & 10 & $49,60 \pm 12,66$ & $46,90 \pm 5,08$ \\
\hline Kor Kuvveti $(\mathrm{sn})$ & 10 & $142,30 \pm 21,06$ & $159,80 \pm 28,12$ \\
\hline
\end{tabular}

Tablo 4' de kontrol grubunda yer alan sporcuların fiziksel ölçümlerin ortalamaları verilmiştir. Ön testte alınan parametrelerden kilo, VKİ ve dikey sıçrama ortalamalarının son testte düştüğü, diğer parametrelerin artı̆g görülmüştür. 
Tablo 5. Kontrol grubunun ölçüm öncesi ve sonrası fiziksel parametrelerinin karşılaştırılması

\begin{tabular}{|c|c|c|c|c|c|c|}
\hline \multicolumn{2}{|c|}{$\begin{array}{l}\text { Antrenman Öncesi ve Sonrası } \\
\text { Parametreler }\end{array}$} & \multirow{2}{*}{$\begin{array}{l}\mathbf{n} \\
3^{\mathrm{a}} \\
\end{array}$} & \multirow{2}{*}{$\begin{array}{l}\text { Ortanca } \\
5,33 \\
\end{array}$} & \multirow{2}{*}{$\begin{array}{l}\text { Toplamları } \\
16,00 \\
\end{array}$} & $\mathrm{Z}$ & $\mathbf{P}$ \\
\hline \multirow{4}{*}{ Boy } & Negatif Siralama & & & & \multirow{4}{*}{$-1,217$} & \multirow{4}{*}{,223 } \\
\hline & Pozitif Siralama & $7^{\mathrm{b}}$ & 5,57 & 39,00 & & \\
\hline & Aynı değer & $0^{c}$ & & & & \\
\hline & Toplam & 10 & & & & \\
\hline \multirow{4}{*}{ Kilo } & Negatif Siralama & $3^{\mathrm{a}}$ & 3,67 & 11,00 & \multirow{4}{*}{,- 108} & \multirow{4}{*}{,914 } \\
\hline & Pozitif Siralama & $3^{b}$ & 3,33 & 10,00 & & \\
\hline & Aynı değer & $4^{\mathrm{c}}$ & & & & \\
\hline & Toplam & 10 & & & & \\
\hline \multirow{4}{*}{ VKİ } & Negatif Siralama & $5^{a}$ & 6,20 & 31,00 & \multirow{4}{*}{1,007} & \multirow{4}{*}{314} \\
\hline & Pozitif Siralama & $4^{b}$ & 3,50 & 14,00 & & \\
\hline & Aynı değer & $1^{\mathrm{c}}$ & & & & \\
\hline & Toplam & 10 & & & & \\
\hline \multirow{4}{*}{ Bacak kuvveti } & Negatif Siralama & $1^{\mathrm{a}}$ & 5,00 & 5,00 & \multirow{4}{*}{$-2,293$} & \multirow{4}{*}{,022 } \\
\hline & Pozitif Siralama & $9^{b}$ & 5,56 & 50,00 & & \\
\hline & Aynı değer & $0^{c}$ & & & & \\
\hline & Toplam & 10 & & & & \\
\hline \multirow{4}{*}{ Sirt kuvveti } & Negatif Siralama & $1^{\mathrm{a}}$ & 1,00 & 1,00 & \multirow{4}{*}{$-2,547$} & \multirow{4}{*}{011} \\
\hline & Pozitif Siralama & $8^{b}$ & 5,50 & 44,00 & & \\
\hline & Aynı değer & $1^{\mathrm{c}}$ & & & & \\
\hline & Toplam & 10 & & & & \\
\hline \multirow{4}{*}{$\begin{array}{l}\text { Sağ El } \\
\text { Kavrama Kuvveti }\end{array}$} & Negatif Siralama & $1^{\mathrm{a}}$ & 7,00 & 7,00 & \multirow{4}{*}{$-2,090$} & \multirow{4}{*}{, 037} \\
\hline & Pozitif Siralama & $9^{b}$ & 5,33 & 48,00 & & \\
\hline & Aynı değer & $0^{c}$ & & & & \\
\hline & Toplam & 10 & & & & \\
\hline \multirow{4}{*}{$\begin{array}{l}\text { Sol El } \\
\text { Kavrama Kuvveti }\end{array}$} & Negatif Siralama & $4^{\mathrm{a}}$ & 4,75 & 19,00 & & \\
\hline & Pozitif Sıralama & $6^{\mathrm{b}}$ & 6,00 & 36,00 & -866 & 386 \\
\hline & Aynı değer & $0^{c}$ & & & , , & (500 \\
\hline & Toplam & 10 & & & & \\
\hline & Negatif Siralama & $1^{\mathrm{a}}$ & 7,50 & 7,50 & & \\
\hline Uzan Eris & Pozitif Sıralama & $8^{\mathrm{b}}$ & 4,69 & 37,50 & -1779 & 075 \\
\hline & Aynı değer & $1^{\mathrm{c}}$ & & & $-1,1 / 19$ & \\
\hline & Toplam & 10 & & & & \\
\hline & Negatif Siralama & $5^{\mathrm{a}}$ & 6,20 & 31,00 & & \\
\hline Dikey Sicrama & Pozitif Siralama & $4^{\mathrm{b}}$ & 3,50 & 14,00 & -1007 & 314 \\
\hline Dikey sçranta & Aynı değer & $1^{c}$ & & & $-1,00 \%$ & (514 \\
\hline & Toplam & 10 & & & & \\
\hline & Negatif Siralama & $2^{\mathrm{a}}$ & 2,25 & 4,50 & & \\
\hline Kor Kuyveti & Pozitif Siralama & $6^{\mathrm{b}}$ & 5,25 & 41,50 & -1893 & 058 \\
\hline nor nuvvel & Aynı değer & $2^{c}$ & & & $-1,090$ & , \\
\hline & Toplam & 10 & & & & \\
\hline
\end{tabular}

a. Antrenman sonrası < antrenman öncesi

b. Antrenman sonrası > antrenman öncesi

c. Antrenman sonras $1=$ antrenman öncesi 
Tablo 5'de antrenman öncesi ve antrenman sonrası ölçüm değerlerine baktığımızda kontrol grubunda boy değişkeninde negatif yönde azalan 3 ve pozitif yönde artan 7 olmuştur. Antrenman grubunun aynı kiloda olanlar 4 , kilosu negatif yönde azalan 3 ve pozitif yönde $\operatorname{artan} 3$ olmuştur. VKİ ve dikey sıçrama değerleri aynı olan 1, negatif yönde azalan 5 ve pozitif yönde artan 4 olmuştur. Bacak kuvveti ve sağ el kavrama kuvveti değerleri negatif yönde azalan 1 ve pozitif yönde artan 9 olmuştur. Sırt kuvveti ve uzan eriş değerleri aynı olan 1, negatif yönde azalan 1 ve pozitif yönde artan 8 olmuştur. Sol el kavrama kuvveti değerleri, negatif yönde azalan 4 ve pozitif yönde artan 6 olmuştur. Kor kuvveti değerleri aynı olan 2, negatif yönde azalan 2 ve pozitif yönde artan 6 olmuştur. Sirt, bacak ve sağ kavrama kuvveti değerlerinde anlamlı bir farklılık vardır $(\mathrm{p}<0,05)$. Kontrol grubunun diğer değişkenleri arasinda anlamlı farklılık bulunmamıştır ( $\mathrm{p}>0,05)$.

\section{Tartışma ve Sonuç}

Çalışmada güreşçilere uygulanan 8 hafta kor kuvvet antrenmanın etkisi incelenmiştir. Antrenman sonunda yapılan fiziksel ölçümlümler sonucunda, sporcuların boylarının uzaması ve anlamlı farklılığın oluşması sporcu grubunun gelişim çağında olmasından dolayı oluşabileceği düşünülmektedir (Tablo 3). VKİ değişkeninde anlamlılık sporcuların boy değişkenindeki artıştan kaynaklandığını düşünmekteyiz. Çalışmada uygulanan kor kuvvet antrenmanının, bireyler üzerinde sırt kuvvetine olumlu etkisi olduğu söylenebilir.

Kor kuvvet antrenmanının kilo, uzan eriş, bacak, sağ ve sol el kavrama, dikey sıçrama ve kor bölgesi kuvveti değişkenlerinde sporcularda antrenman sonunda ortalamaları değişse de olumlu etkisi olduğunu söyleyemeyiz.

Durna (2017) güreşçilere 8 haftalık kor egzersizlerin bazı performans parametrelerine etkisini araştırmak amacıyla çalışma yapmıştır. Bu çalışma sonucunda istatistiksel olarak vücut ağırlı̆̆ına ve VKİ değerlerine istatistiksel olarak anlamlı bir etki etmediği belirlenmiş olmasına rağmen, kontrol grubunda vücut ağırlığında ve VKİ değerlerinde anlamlı olmayan bir düşüş gerçekleşmiştir. Antrenman grubunda vücut ağırlığında bir artış meydana geldiği ve VKİ değerlerinde anlamlı bir değişiklik olduğu tespit edilmiştir. Doğan, Mendeş, Akcan ve Tepe (2016) 8 haftalık kor antrenmanın futbolcuların 
fiziksel ve fizyolojik parametreleri üzerine etkisi araştırmışlar ve vücut kompozisyonu, bacak kuvveti, sırt kuvveti, esneklik, dikey sıçrama ölçümleri almışlardır. Antrenman grubunun ön test ve son test değerleri karşılaştırıld1ğında tüm parametrelerde anlamlı bir iyileşme gözlenmiştir. Kontrol grubunun ön test ve son test değerleri karşılaştırıldığında VKİ, vücut ağırlığı, dikey sıçrama, bacak ve sırt kuvveti değerlerinde anlamlı bir iyileşme gözlenmiştir. Gruplar arası farklarda; ağırlık, VKİ, esneklik, bacak ve sırt kuvveti çalışma grubunun lehine anlamlılık saptanmıştır. Hançerlioğulları (2020) 6 haftalık pliometrik ve kor egzersizlerinin bireysel ve takım sporcularının üzerine yaptığ 1 çalışmasında, Bireysel spor yapanların ön test ve son test değerlerinin karşılaştırılmasında vücut ağırlığı, VKİ, sol ve sağ kavrama kuvveti, esneklik, dikey sıçrama ve denge parametresinde istatistiksel olarak anlamlı farklılık bulmuştur. Dilber vd. (2016) , yapmış olduğu çalışmada 16 futbolcuya 8 haftalık kor antrenmanı uygulamış, çalışma sonucunda motorik özelliklerde; sağ el kavrama, denge, dikey sıçrama mesafesi, esneklik, anaerobik güç sırt kuvveti, plank, $\mathrm{t}$ testi ve illinois testi ölçüm sonuçları arasında istatistiksel açıdan anlamlı farklılık tespit ediliştir ( $\mathrm{p} \leq 0,05)$. Dedecan (2016) çalışmasında adolesan erkek öğrencilerde 8 haftalık kor antrenmanları uyguladı. Antrenman öncesi ve sonrası boy uzunluğu, vücut ağırlığı, bacak ve sırt kuvveti, sağ ve sol el kavrama kuvveti, durarak uzun atlama, deri altı yağ kalınlığı, dikey sıçrama, 20 metre mekik koşusu (Shutlle Run Test), 1dk. şınav ve mekik, ölçümleri ve testleri uyguland.. Antrenman grubunun ön test ve son test değerleri karş1laştırıldığında aerobik güç hariç tüm parametrelerde istatistiksel açıdan anlamlı bir fark gözlemlemiştir. Bu çalışmayla Doğan vd. (2016) çalışması arasında antrenman grubunun bacak kuvveti değişkeni arasında farklılıklar olduğu göze çarpmaktadır. Bu farklılık Doğan vd. (2016) çalışmasında kullandığ1 antrenman yönteminden kaynaklandığı söylenebilir. Kor egzersizle ilgili çalışmalar incelendiğinde bu çalışmanın bulgularıyla benzerlikler mevcuttur (Durna, 2017, s.35; Doğan vd., 2016, s.10 ; Hançerlioğulları, 2020, s.14 ). Bu benzerliklerin kor antrenman yönteminin birçok spor branşında yaygın olarak kullanılması ve kor antrenmanın sporcu gruplarında kuvvete, esenkliğe ve sıçrama yeteneğine olumlu etkilerinden kaynaklandığını düşünmekteyiz.

Güreşte fiziksel uygunluk parametreleri maksimal dinamik kuvvet, izometrik kuvvet, patlayıcı kuvvet ve kuvvette devamlılık yüksek seviyedeki güreş performansıyla yakından ilgilidir (Chaabene vd., 2017, s. 1411). Tüm 
bunlar dikkate alındığında güreşte performansın kor bölge kuvvetini yansıtan gövde stabilitesi, fonksiyonel hareketlilik ve üst ekstremite dengesinden etkilenmektedir. Güreşçilerde performansın artışını desteklemek statik ve dinamik postürlerini korumak için yüksek performansa aday sporcularda kuvvet, esneklik, dayanıklılık, kor bölge çalışmalarına sporcuların ihtiyacına göre yer vermeleri gerektiğini göstermektedir (Alper ve Eroğlu-Kolayiş, 2020, s.48).

Bu çalışmadaki kontrol grubu ön testte alınan parametrelerden kilo, VKİ ve dikey sıçrama ortalamalarının son testte düştügü̈, boy, uzan eriş, bacak, sırt, sağ ve sol el kavrama ve kor kuvveti ortalamalarının artığı görülmüştür (Tablo 4). Ayrıca kontrol grubunda sırt, bacak ve sağ kavrama kuvveti değerlerinde anlamlı bir farklılık vardır. Kontrol grubunda anlamlı farklılığın olması, bu grubun haftada 6 gün güreş antrenmanı yapmasından kaynaklanabileceğini söyleyebiliriz. Kontrol grubunun VKİ, kilo, boy, dikey sıçrama, uzan eriş, sol el kavrama ve kor kuvveti arasında anlamlı farklılık bulunmamıştır (Tablo 5).

Sonuç olarak 8 haftalık kor kuvvet antrenmanlarının serbest stil erkek güreşçilerin sırt kuvveti üzerine olumlu etkileri olduğu söylenebilir. Çalışma sonucunda kuvvet gelişimi hedeflenen güreşçi gruplarına bu çalışmada uygulanan antrenman program uygulanabileceği önerilebilir. 


\section{EXTENDED ABSTRACT}

\section{Investigation of The Effects of 8 Weeks of Core Exercises on Maximal Strength, Vertical Jump and Flexibility in Free Style Wrestlers}

Ercan Tural - Sedat Kahya - Abdullah Tiryaki-Mehmet Çebi - Levent Ceylan Ondokuz Mayis University, Sivas Ahmet Ayık Sports High School, Sivas Cumhuriyet University

Improving core strength in the development of sportive performance is a topic that is frequently discussed in training science. Strong core muscles are essential for a successful sportive performance as well as our ability to maintain our daily routine activities. Core is defined as the main center of the body that initiates all movements as the strong field. Core strength is an important muscular structure in maintaining the function of the spine. The core is a large muscle that is used for the lumbopelvic region or body part of the body, including the abdominal muscles in the front, the back muscles in the back, the diaphragm in the front and the pelvic floor muscles below. Strengthening this muscular structure with the help of exercises is very important for sportive performance. Core strength exercises are a method that balances the hip and spine and is often used in most strength exercises. On the other hand, core exercises are an application that also improves the strength of the athlete against resistance. Today, core is a popular target for improving athletic performance, as well as a structure that helps distal mobility for proximal stability. Core exercises are a mandatory practice to prevent injuries and for a proper performance. Core, which has a great importance in many sports branches, especially in wrestling, one of the most popular sports branches in the world, the athlete's ability to produce great strength and muscle power for both the lower and upper body is great in terms of sportive performance, motor capacity, balance development, rehabilitation and injury prevention, has an importance.

In addition, core exercises provide support to increase functional strength with dynamic balance. Wrestling, which is one of the great physical activities of human history, is an important factor in developing a strong core strength 
for a good balance performance due to the frequent application of movements such as pushing, pulling and falling to the ground, as well as the soft structure of the ground where the competitions and training are held. Especially freestyle wrestling is of great importance for core strength as it is a short-term, intermittent and high-intensity activity involving the upper and lower parts of the body.

We can say that core training has important effects on Wrestling as in many other branches. The aim of our study is to examine the maximal strength, vertical jump and flexibility levels of freestyle wrestlers between the ages of 15-17 after 8-week core exercises. It is important to determine the relationship between regular core exercises and maximal strength, flexibility and vertical jumping skills of freestyle wrestlers in terms of determining the training programs to be applied to young athletes. For this reason, the aim of the study is to determine the effect of regular core exercises performed after freestyle wrestling training on maximal strength, flexibility and vertical jumping skills.

The purpose of this study; To examine the effects of 8-week core exercises on maximal strength (leg, back and paw strength), vertical jump and flexibility, applied to freestyle contestant athletes between 15-17 years of age at Sivas Ahmet Aylk Thematic Sports High School. A total of 20 freestyle wrestlers, 10 training and 10 control groups, with an age of $15.80 \pm 0.616$ and sports age of $4.05 \pm 1.538$, participated in the study. The measurements of the athletes' height, body weight, core strength and stability, vertical jump, reach and back, leg and claw strength as pre-test and post-test were taken. Wilcoxon test and descriptive analysis test were used to determine the change in training and control groups before and after exercise. Considering the averages of the physical measurements of the participants after the core strength training, it was seen that the averages of weight, BMI and left hand grip strength decreased and other parameters increased. When we look at the measurement values before and after training, there is a significant difference in back strength, height and BMI values $(\mathrm{p}<0.05)$. There was no significant difference between the other variables of the individuals ( $p>0.05)$. When we look at the averages of physical measurements of the athletes in the control group, it was seen that the average weight, BMI and vertical jump of the parameters taken in the pretest decreased in the post-test, and the other parameters increased. When we look at the measurement values before and after training, there is a significant 
difference in back, leg and right grip strength values in the control group ( $p$ $<0.05)$. There was no significant difference between other variables of the control group ( $p>0.05$ ). As a result, it can be said that 8-week core strength training has positive effects on back strength of freestyle male wrestlers.

\section{Kaynakça / References}

Afyon, Y. A. (2014). Effect of core training on 16 year-old soccer players. Academic Journals, 9, 1275-1279.

Alper, E. ve Eroğlu-Kolayiş, İ. (2020). Yıldız güreşçilerde güreş performansı ile gövde stabilitesi, dinamik denge ve fonksiyonel hareketlilik değerleri arasindaki ilişkinin incelenmesi. CBÜ Beden Ĕ̆itimi ve Spor Bilimleri Dergisi, 15(1), 48-66.

Atan, T., Kabadayı, M., Eliöz, M., Çilhoroz, B. T. ve Akyol, P. (2013). Effect of jogging and coretraining after supramaximal exercise on recovery. Turkısh Journal of Sport and Exercise, 15, 73-77.

Bal, B. S., Singh, L., Singh, G. ve Singh, B. (2018). Norms and grades under normal distribution for basic movement patterns of freestyle wresting player. $\mathrm{Eu}$ ropan Journal of Physical Education and Sport Science, 4, 100-108.

Bayati, R., Majelan, A. S., Mirzeali, B. ve Barbas, I. (2019). The Effect of 12 weeks of wrestling warm-up program on functional movement screen scores in cadet westlers. Ann Appl Sport Sci, 7, 40-46.

Becer, E., ve Eliöz, M. (2020). Elit Düzey erkek yüzücülerde 16 haftalık core egzersizlerinin solunum fonksiyonlarma etkisi. Uluslararası Sosyal Araştırmalar Dergisi, 13, 891-894.

Chaabene, H., Negra, Y., Bouguezzi, R., Mkaouer, B., Franchini, E., Julio, U. ve Hachana, Y. (2017). Physical and physiological attributes of wrestlers: An update. Journal of Strength and Conditioning Research, 31(5), 1411-1442

Dedecan, H. (2016). Adolesan dönem erkek öğrencilerde core antrenmanlarmmı bazı fiziksel ve fizyolojik özellikleri üzerine etkisi (yüksek lisans tezi, Selçuk Üniversitesi Sağlık Bilimleri Enstitüsü).

Demirkan, E., Kutlu, M., Koz, M., Özal, M. ve Favre, M. (2014). physical fitness differences between freestyle and greco-roman junoir wrestlers. Journal of $\mathrm{Hu}$ man Kinetics, 41, 246-250.

Dilber, A.O., Lağap, B., Akyüz, Ö., Çoban, C., Akyüz, M., Taş, M. ve Özkan, A. (2016). Erkek futbolcularda 8 haftalık kor antrenmanının performansla ilgili fiziksel uygunluk değişkenleri üzerine etkisi. CВÜ Beden Eğitimi ve Spor Bilimleri Dergisi, 11(2), 77-82. 
Doğan, G., Mendeş, B., Akcan, F. ve Tepe, A. (2016). Futbolculara uygulanan sekiz haftalık core antrenmanın bazı fiziksel ve fizyolojik parametreler üzerine etkisi. Beden Egitimi ve Spor Bilimleri Dergisi, 10(1), 1-12

Durna M. (2017). 8 haftalik core egzersiz programının güreşçilerde denge, esneklik ve çeviklik düzeyleri üzerine etkisi. (Yayımlanmamış yüksek lisans tezi). Gazi Üniversitesi Antrenörlük Eğitimi Anabilim Dall, Ankara.

Gür, F. ve Ersöz, G. (2017). Kor antrenmanın 8-14 yaş grubu tenis sporculrının kor kuvveti, statik ve dinamik denge özellikleri üzerindeki etkisinin değerlendirilmesi. Spormetre, 15, 130-137.

Hançerlioğulları B. (2020) 6 haftalik pliometrik ve core egzersizlerinin bireysel ve takım sporcularnnda denge faktörü üzerine etkisi. (Yayımlanmamış yüksek lisans tezi). İstanbul Gelişim Üniversitesi Lisansüstü Eğitim Enstütüsü Antrenörlük Eğitimi Anabilim Dalı, İstanbul.

İri, R., ve Aktuğ, Z. B. (2018). 12-15 yaş arası güreşçilerde 8 haftalık denge antrenmalarınn denge çeviklik ve sürat performansı üzerine etkisi. Spor Bilimleri Dergisi, 3, 81-90.

Karacabey, K., Tetik, G., Kartal, R., Çağlayan, A., ve Kaya, K. (2016). Analysis on the effect of core training program on some physical and motoric characteristics for female volleyball players aged 8-11. СВÜ Beden Eğitimi ve Spor Bilimleri Dergisi, 11, 63-68.

Kibler, W. B., Press, J. ve Aaron, S. (2006). The Role of core stability in athletic function. Sport Medicine, 36, 189-198.

Küçük H. (2020). Kadın futbolcularda statik ve dinamik dengenin mevkilere göre karşılaştırılması. Uluslararası Spor Egzersiz ve Antrenman Bilimi Dergisi, Supp.(4), 53-56.

Küçük, H. ve Erim, V. (2021). Elit judo ve güreş̧̧ilerin denge performanslarının karşılaştırılması. ROL Spor Bilimleri Dergisi, 2021, 2(1), 1-7.

Mackenzie, B. (2005). 101 performance evaluation tests. London: Electric Word plc 6771 Goswell Road London EC1V 7EP.

McGill, S. (2020). Core training:evidence translating to better performance and injuiry prevention. National Strength and Conditioning Association, 32, 33-46.

Mirzaelı, B., Curby, D. G., Rahmanı-Nıa, F., ve Moghadası, M. (2009). Physiological profile of elite iranian junior freestyle wrestlers. Journal of Strenght and Conditioning Research, 23(8), 2339-2344.

Reed, C. A., Ford, K. R., Myer, G. D. ve Hewett, T. E. (2014). The effect of 1solated and integrated core stability training on athletic performance measures. Sports Medicine, 42 (8), 697-706. 
Samson, K. M. ve Sandery, M. A. (2007). A core stabilization training program for tennis athelets. Human Kinetics, 12, 41-46.

Sever, O., Kır, R. ve Yaman, M. (2017). 11-13 yaş arası erkek tenisçilerde periyotlanmış core antrenman progrmının isabetli servis hızına etkisi. Journal of $\mathrm{Hu}$ man Sciences, 14(3), 3023-3030.

Willardson, J. (2014). Developing the core. NSCA: National Strength and Conditioning Association.

\section{Kaynakça Bilgisi / Citation Information}

Turan, E., Kahya, S., Tiryaki, A. ve Çebi, M. Ceylan, L.(2021) Serbest stil güreşçilerde 8 haftalık core egzersizlerinin maksimal kuvvet, dikey sıçrama ve esneklik üzerine olan etkisinin incelenmesi. OPUSUluslararası Toplum Araştırmaları Dergisi , 17(37), 4563-4580. DOI: 10.26466/opus. 856167 